\title{
Opportunistic Infections in Patients with Temporal Arteritis Treated with Corticosteroids
}

\author{
Sara A. Hedderwick, MRCP, Hector F. Bonilla, MD, Suzanne F. Bradley, MD, and \\ Carol A. Kauffman, MD
}

$\mathrm{T}$ emporal arteritis and polymyalgia rheumatica, different clinical manifestations of the same systemic granulomatous vasculitis, predominantly affect older persons. ${ }^{1}$ Huston and colleagues estimated the prevalence to be 1 in 750 persons older than 50 years of age. ${ }^{1}$ Temporal arteritis often requires high and sometimes sustained corticosteroid therapy to prevent the development of sight threatening complications. ${ }^{1-7}$ Often, corticosteroids alone are used for the entire length of the treatment course, which may exceed 1 year. This is in contrast to other collagen vascular diseases/vasculitides, in which other steroid-sparing immunosuppressive agents are used in combination to reduce the dose of corticosteroids. ${ }^{8}$

Corticosteroids exert their immunosuppressive effect principally on cell-mediated immunity. ${ }^{9}$ This arm of the immune system is particularly important for defense against a variety of different intracellular pathogens. Thus, patients receiving corticosteroid therapy are at increased risk of infection caused by intracellular organisms. Although intracellular pathogens are frequently thought of in the differential diagnosis of pneumonia and sepsis syndrome in patients with hematological malignancies or transplants, these types of pathogens are rarely considered in the differential diagnosis of patients with temporal arteritis. We report the cases of three patients who received corticosteroids for temporal arteritis and who subsequently were infected with opportunistic pathogens. In all three, the opportunistic infection was not considered with the initial diagnosis.

\section{CASE REPORTS}

\section{Case 1}

A 77-year-old man was diagnosed as having temporal arteritis in October 1994. He was treated with $60 \mathrm{mg}$ prednisone daily and showed improvement in his symptoms of headache and muscle weakness. His prednisone dosage was reduced to $40 \mathrm{mg}$ by January 1995 . In February 1995 , he was admitted to hospital for the treatment of pneumonia. Chest roentgenogram revealed bibasilar patchy infiltrates. Treatment with ceftriaxone and erythromycin followed by amoxicillin/clavulanic acid and clarithromycin failed to clear the chest roentgenogram findings. He had several subsequent hospitalizations over the next 3 months for the treatment of

From the Divisions of Infectious Diseases and Geriatric Medicine, Department of Internal Medicine, Department of Veterans Affairs Medical Center, University of Michigan Medical School, Ann Arbor, Michigan.

Address correspondence and reprint requests to Sara A. Hedderwick, MRCP,

Veterans Affairs Medical Center, 2215 Fuller Rd. Ann Arbor, MI.
Clostridium difficile colitis, funguria, and a Pseudomonas aeruginosa and enterococcal urinary tract infection.

In July 1995, the patient was admitted to hospital with dyspnea, difficulty walking, and vomiting. He was taking 25 mg prednisone daily. On examination, he had a temperature of $98.5^{\circ} \mathrm{F}\left(37.1^{\circ} \mathrm{C}\right)$, and respirations were $28 / \mathrm{min}$. He was alert but distractable and had no signs of meningismus. Neurological exam revealed intact cranial nerve function and normal peripheral power and sensation with symmetrical reflexes. The hemoglobin was $12.4 \mathrm{~g} / \mathrm{dL}$, white blood cell count was $16,900 / \mathrm{mm}^{3}$, platelets were $25,000 / \mathrm{mm}^{3}$. Chest roentgenogram revealed persistent bilateral, patchy infiltrates, predominantly affecting the lower lobes (Figure 1).

Bronchoscopy was performed, and transbronchial biopsy revealed chronic inflammation and budding yeasts. Culture of bronchoalveolar fluid yielded Cryptococcus neoformans. Cerebrospinal fluid microscopy showed budding yeasts, cryptococcal antigen was positive at a titer of 1:2048, and culture was positive for C. neoformans. Urine culture was positive for C. neoformans, but serum cryptococcal antigen titer was negative. The patient was treated with 6 weeks of amphotericin B $(0.4 \mathrm{mg} / \mathrm{kg} / \mathrm{d})$ plus flucytosine (adjusted for renal function). After completion of this therapy, fluconazole $50 \mathrm{mg}$ daily (adjusted for creatinine of $2.3 \mathrm{mg} /$ $\mathrm{dL}$ ) was begun. Although his pulmonary and mental status improved on this regimen, he died at home 4 weeks after discharge, and autopsy was not obtained.

\section{Case 2}

A 71-year-old man was diagnosed with temporal arteritis in August 1995. He was prescribed a dosage of $60 \mathrm{mg}$ of Prednisone daily, with improvement of diplopia and visual loss. In October 1995, he was admitted to hospital with cellulitis of his right lower extremity and a malleolar ulcer attributable to peripheral vascular disease. Following intravenous antibiotics and debridement, he was admitted to the Geriatric Evaluation and Management service for rehabilitation.

In November 1995, while on a daily dosage of $40 \mathrm{mg}$ prednisone, the patient became dyspneic, with rigors and a fever of $100.4^{\circ} \mathrm{F}\left(38^{\circ} \mathrm{C}\right)$. White blood cell count was $9600 /$ $\mathrm{mm},{ }^{3}$ (86\% neutrophils), and hemoglobin was $15.4 \mathrm{~g} / \mathrm{dL}$. A chest roentgenogram revealed diffuse bilateral infiltrates (Figure 2). Ampicillin/sulbactam, 1.5 g every 8 hours, was begun. His condition deteriorated and he was transferred to the intensive care unit where arterial blood gases showed $\mathrm{pH} 7.5$, $\mathrm{PaO}_{2} 61 \mathrm{~mm} \mathrm{Hg}, \mathrm{PaCO}_{2} 28 \mathrm{~mm} \mathrm{Hg}$ on $100 \% \mathrm{O}_{2}$ face mask. 


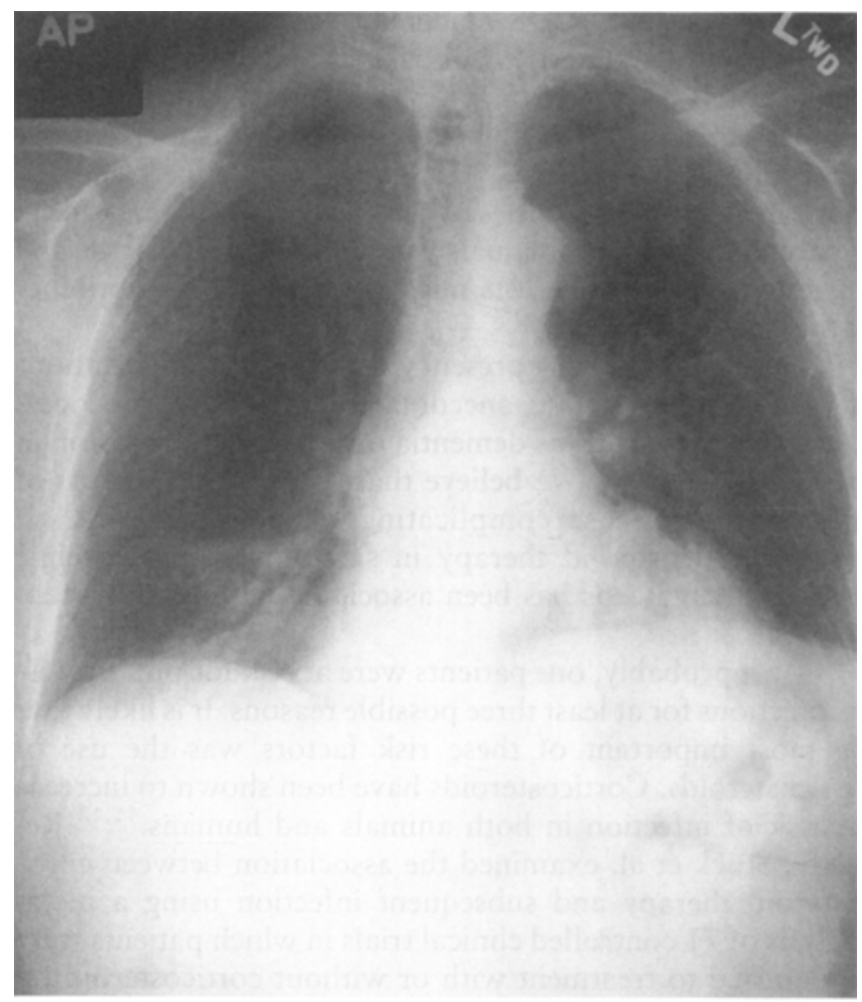

Figure 1. Chest roentgenogram showing bilateral patchy infiltrates attributable to Cryptococcus neoformans (Case 1).

The following day he underwent bronchoscopy. Cytological examination of the bronchoalveolar fluid revealed many Pneumocystis carinii organisms. Despite treatment with intravenous trimethoprim/sulphamethoxazole therapy $(15 \mathrm{mg} /$ $\mathrm{k} / \mathrm{d}$ ), the patient's condition did not improve. His course was complicated by a myocardial infarction, the development of acute renal failure, $P$. aeruginosa pneumonia, and an upper gastrointestinal bleed. He died 17 days after admission to the intensive care unit.

\section{Case 3}

A-74-year old man was admitted in August 1995 for the treatment of a urinary tract infection caused by Serratia marcescens and osteomyelitis underlying a malleolar ulcer. His medical history was significant for insulin-requiring diabetes mellitus with nephropathy, hypothyroidism, and hypertension. In October 1995, he complained of blurred vision and jaw claudication, and examination revealed left temporal artery tenderness. A presumptive diagnosis of temporal arteritis was made, based on his clinical picture and a temporal artery biopsy, which was suggestive, but not diagnostic, of temporal arteritis. His symptoms responded well to prednisone $60 \mathrm{mg}$ daily, and 14 days into corticosteroid therapy, the Westergren sedimentation rate had fallen from 110 to 25 $\mathrm{mm} / \mathrm{h}$. Prednisone was gradually tapered such that he was receiving $40 \mathrm{mg}$ daily by November 1995 . On Novmber 27 , 1995 , he developed stupor, dyspnea, and a temperature of $101^{\circ} \mathrm{F}\left(38.3^{\circ} \mathrm{C}\right)$. Despite the correction of his blood glucose of $24 \mathrm{mg} / \mathrm{dL}$ to normal, his somnolence did not improve. His hemoglobin was $13.5 \mathrm{~g} / \mathrm{dL}$, white blood cell count was $18,900 / \mathrm{mm}^{3}$, and platelets were $126,000 / \mathrm{mm}^{3}$ Arterial blood gases showed a $\mathrm{pH}$ of $7.5, \mathrm{PaO}_{2} 49 \mathrm{mmHg}, \mathrm{PaCO}_{2} 38.5$ $\mathrm{mmHg}$ and bicarbonate of $30 \mathrm{mmol} / \mathrm{L}$ on room air. A chest



Figure 2. Chest roentgenogram showing diffuse interstitial disease with patchy infiltrates attributable to Pneumocystis carinii (Case 2).

roentgenogram showed left perihilar air space disease, and sputum sample revealed $>25$ white blood cells per high powered field, moderate Gram positive bacilli, and few Gram positive cocci; culture yielded only normal flora. Four blood culture bottles yielded Listeria moncytogenes. He responded well to ampicillin, $2 \mathrm{~g}$ intravenously every 4 hours, for 21 days and was discharged to home on prednisone $20 \mathrm{mg} / \mathrm{d}$ in January 1996.

\section{DISCUSSION}

These three cases illustrate that patients in whom temporal arteritis is treated with corticosteroids are at increased risk of infection with opportunistic pathogens such as $P$. carinii, L. monocytogenes, and C. neoformans. Increasingly, there is recognition that these organisms are widely distributed in the environment and can be acquired easily. However, disease occurs almost entirely in patients who are immunocompromised. ${ }^{10-14}$

Various reports have suggested that mortality in patients with temporal arteritis is increased compared with the normal age-matched population. ${ }^{2-4,15}$ Other authors have not shown such an increase in mortality. ${ }^{5-7}$ However, if mortality is increased, it is unclear if such an increase is related to the disease itself or complications of its treatment. Longitudinal cohort studies which contain small numbers of patients do not show statistically significant increases in infection rates for patients who have temporal arteritis and who are treated with corticosteroids, when compared with the normal population, ${ }^{2,5,7}$ Anecdotal reports of opportunistic infections reported in temporal arteritis have included invasive aspergillosis, ${ }^{16,17}$ nocardiasis, ${ }^{18}$ tuberculosis, ${ }^{6,19}$ varicella-zoster infection $^{17}$ and pneumocystis pneumonia. ${ }^{20,21}$

$P$. carinii pneumonia (PCP) has become increasingly important with the epidemic of acquired immune deficiency syndrome (AIDS). ${ }^{22}$ However, this organism is a recognized complication of many other immunodeficiency states, including immunoglobulin deficiencies, malnutrition, hematological malignancies, and transplantation. ${ }^{23-28}$ Moreover, with the advent of significant immunosuppressive regimens for many rheumatological and dermatological disorders, the in- 
cidence of PCP in patients with these diseases has increased in recent years. ${ }^{29}$

Crayton and Sundstrom reported a case of PCP occurring in a 71-year-old man who had temporal arteritis and who had received corticosteroids for 5 weeks. ${ }^{20}$ In a retrospective review of all non-AIDS-associated episodes of PCP diagnosed at the Mayo Clinic between 1985 and 1991, Yale and Limper described five cases of PCP in patients with temporal arteritis. ${ }^{21}$ Other retrospective reviews of PCP do not report PCP occurring in patients with temporal arteritis $^{23-26}$ although patients with other collagen vascular disorders, such as Wegener's granulomatosus, systemic lupus erythematosus, dermatomyositis, and rheumatoid arthritis have been reported with PCP. ${ }^{27,28}$

Prophylaxis against PCP has become standard treatment for patients with AIDS and acute leukemia and following transplantation. However, prophylaxis is not recommended routinely for patients undergoing treatment of connective tissue/collagen vascular disorders, inflammatory bowel disease, or dermatological conditions. Sepkowitz et al. have suggested that reasons for changes in the spectrum of underlying disorders seen in patients with PCP over time, in part, reflect this changing use of prophylaxis. ${ }^{30}$ There is still no concensus regarding the use of prophylaxis against PCP with trimethoprim/sulphamethoxazole in patients with temporal arteritis treated with corticosteroids. Because the numbers of infections in patients with temporal arteritis caused by $P$. carinii is small, the risk of side effects from the trimethoprim/ sulphamethoxazole may outweigh the benefits obtained by routine use of the drug.

L. monocytogenes has been reported rarely as a complication of temporal arteritis. Pigrau et al. noted in a brief communication that five of 51 adults with listeriosis had "systemic lupus erythematosus or Horton's (temporal) arteritis," but no specific patient data were reported. ${ }^{31}$ This lack of cases is perhaps surprising given the incidence of listeriosis throughout the world. Skogberg, et al. described 74 patients with Listeria infection in Finland; five of these patients had collagen vascular disorders. ${ }^{11}$ Kraus et al. described eight patients who had collagen vascular diseases other than temporal arteritis and who developed listeriosis. ${ }^{32}$ Of 57 adults with listeriosis in an outbreak associated with soft cheese ingestion in Switzerland, none had vasculitis. ${ }^{33}$ Although not specifically reported, it seems likely that any patient with listeriosis complicating temporal arteritis could have been grouped with "collagen vascular disorders" in previous series.

There is clearly an increased risk of listeriosis with increasing age. ${ }^{12}$ The Centers for Disease Control and Prevention have estimated that sporadic cases of Listeria infection occur in the United States at a rate of 7.1 per $10^{6}$ population per year. ${ }^{12}$ Excluding pregnancy-associated cases, the incidence is lowest and relatively constant during the first $\mathbf{4}$ decades of life and increases thereafter. By age 70, the incidence is 21 cases per $10^{6}$ population. Although this increase in incidence may be explained by a waning immune system in older people, it is just as likely that decreasing gastric acidity allows a larger inoculum of this food-borne pathogen to pass through the stomach and cause disease. ${ }^{34,35}$

C. neoformans is an encapsulated yeast that most commonly causes chronic meningitis. ${ }^{14,36}$ It appears that intact cell-mediated immune systems are important host defenses against this organism. The incidence of cryptococcosis has increased with the AIDS epidemic ${ }^{14}$; in non-HIV-infected people, common underlying diseases include lymphoma, leukemia, and transplantation. ${ }^{14,36,37}$ However, in the non-HIV population, up to $50 \%$ may have no known associated immunosuppressive disease. ${ }^{13}$ Schimpff and Bennett showed subtle in vitro abnormalities of cell-mediated immunity in six apparently normal individuals with cryptococcal disease and suggested that these defects might explain the susceptibility to this fungus. ${ }^{38}$

The older adult may present with atypical manifestations of meningitis; there are anecdotal reports of cryptococcal meningitis presenting as dementia or new onset confusion in the older adult. ${ }^{39,40}$ We believe that there are no reports of cryptococcal disease complicating temporal arteritis although corticosteroid therapy in sarcoidosis and systemic lupus erythematosus has been associated with cryptococcosis. ${ }^{14,36,37}$

Most probably, our patients were at risk for opportunistic infections for at least three possible reasons. It is likely that the most important of these risk factors was the use of corticosteroids. Corticosteroids have been shown to increase the risk of infection in both animals and humans. ${ }^{41,42} \mathrm{Re}$ cently, Stuck et al. examined the association between corticosteroid therapy and subsequent infection using a metaanalysis of 71 controlled clinical trials in which patients were randomized to treatment with or without corticosteroids. ${ }^{43}$ The relative risk of infection was 1.6 (confidence interval $0.9-2.3$ ) in patients receiving corticosteroids but was greater in those with underlying neurological disease. This effect was cumulative and dose-dependent. No increased rate was seen in those receiving $<10 \mathrm{mg}$ daily or $<700 \mathrm{mg}$ total. At the cellular level, corticosteroid therapy inhibits T-lymphocyte function and IL-2 production and suppresses monocyte function and production. ${ }^{9}$

The use of corticosteroids has been shown to contribute to the risk of infection with $P$. carinii and C. neoformans in both animals and humans. ${ }^{10,13,44}$ Successful infection of rats with $P$. carinii requires the animals to be treated with corticosteroids in order to produce pneumonia. ${ }^{10}$ Experimental animal studies have shown a decrease in the size of the inoculum required to induce $L$. monocytogenes infection in steroid-treated rats when compared with rats not treated with corticosteroids. ${ }^{45}$

Secondly, our patients were all more than 65 years of age. Aging has been shown to decrease cell-mediated immunity in both animal models and humans. ${ }^{46-48}$ Older people have been shown to be at increased risk for many agents, including listeriosis, cryptococcosis, and tuberculosis. ${ }^{2,49,50}$ Age alone is thought to be a sufficient predisposing factor for acquisition of these diseases. No such clearly defined age risk exists for PCP, but interestingly, Jacobs et al. described a cluster of five immunocompetent patients, who were all more than 65 years old and who were diagnosed with PCP. ${ }^{51}$

Thirdly, the presence of temporal arteritis may have contribured to a dysregulation of the immune system with concomitant increased susceptibility to infection. Certainly, macrophage and $T$ cell activation, thought to be related to the disease itself has been found in patients with temporal arteritis. ${ }^{52}$ However, temporal arteritis is a disease which rarely affects those less than 50 years old and in whom high dose corticosteroid therapy is the standard treatment regimen. Thus, ability to dissect the relative contribution to infection from temporal arteritis, therapy, and age is difficult. 
Patients with temporal arteritis often have dramatic symptomatic improvement with corticosteroid therapy. High doses are required to initially control symptoms, and relapses may occur if corticosteroids are tapered too quickly. Patients with temporal arteritis are commonly more than 50 years old and are exposed to long courses of corticosteroids with all their attendant complications in older people, including diabetes mellitus, altered mentation, and osteoporosis. The patient with temporal arteritis is, therefore, at risk from infections that which may be uncommon otherwise, and we should remain cognizant of this possibility. Diagnoses of possible opportunistic infections should be actively pursued to ensure such patients are given appropriate therapy.

\section{REFERENCES}

1. Huston KA, Hunder GG, Kennedy RH, Elveback LR. Temporal arteritis. A 25 year epidemiologic, clinical and pathologic study. Ann Intern Med 1978;88:162-167.

2. Bisgard $\mathrm{C}$, Sloth $\mathrm{H}$, Keiding $\mathrm{N}$, Juel K. Excess mortality in giant cell arteritis. J Intern Med 1991;230:119-123.

3. Nordborg E, Bengtsson BA. Death rates and causes of death in 284 consecutive patients with giant cell arteritis confirmed by biopsy. Br Med J 1989;299:549-550.

4. Nesher G, Sonnenblick M, Friedlander Y. Analysis of steroid related complications and mortality in temporal arteritis: A 15 year survey of 43 patients. J Rheumatol 1994;21:1283-1286.

5. Andersson R, Malmvall BE, Bengtsson BA. Long-term survival in giant cell arteritis including temporal arteritis and polymyalgia rheumatica. $A$ follow-up study of 90 patients treated with corticosteroids. Acta Med Scand 1986;220:361-364.

6. Jonasson F, Cullen JF, Elton RA. Temporal arteritis. A 14 year epidemiological, clinical and prognostic study. Scott Med J 1979;24:111-117.

7. Matteson EL, Gold KN, Bloch DA, Hunder GG. Long-term survival of patients with giant cell arteritis in the American College of Rheumatology giant cell arteritis classification criteria cohort. Am J Med 1996;100:193-196.

8. Luqmani RA, Palmer RG, Bacon PA. Azathioprine, cyclophosphamide and chlorambucil. Baillieres Clin Rheumatol 1990;4:595-619.

9. Boumpas DT, Pagliogianni F, Anastassiou ED, Balow JE. Glucocorticosteroid action on the immune system: molecular and cellular aspects. Clin Exp Rheumatol 1991;9:413-423.

10. Cushion MT, Harmsen A, Matsumoto $Y$ et al. Recent advances in the biology of Pneumocystis carinii. J Med Vet Mycol 1994;32:217-228.

11. Skogberg K, Syrjanen J, Jahkola $M$ et al. Clinical presentation and outcome of listeriosis in patients with and without immunosuppressive therapy. Clin Infect Dis 1992;14:815-821.

12. Gellin BG, Broome CV, Bibb WF et al. The epidemiology of listeriosis in the United States-1986. Listeriosis study group. Am J Epidemiol 1991;133:392401 .

13. Perfect JR, Durack DT, Gallis HA. Cryptococcemia. Medicine 1983;62:98109.

14. Knight FR, Mackenzie DW, Evans BG et al. Increasing incidence of cryptococcosis in the United Kingdom. J Infect 1993;27:185-191.

15. Graham E, Holland A, Avery A, Ross Russell RW. Prognosis in giant call arteritis. Br Med J 1981;282:269-271.

16. Wiggins RE. Invasive aspergillosis. A complication of treatment of temporal arteritis. J Neuroophthalmol 1995;15:36-38.

17. Chmelewski WL, McKnight KM, Agudelo CA, Wise CM. Presenting features and outcomes in patients undergoing temporal artery biopsy. A review of 98 patients. Arch Intern Med 1992;152:1690-1695.

18. Borget C, Gepner P, Piette AM, Chapman A. Abces deltoidien primitif a Nocardia asteroides au cours d'une maladie de Horton traitee. Rev Rhum Mal Osteoartic 1992;59:149-151.

19. Barrier J, Tournemaine N, Maulaz D et al. Evolution, traitement et prognostic de la maladie de Horton. Med Interne 1983;134:428-435.

20. Crayton HE, Sundstrom WR. Pneumocystis carinii pneumonia following corticosteroid therapy for giant cell arteritis. Wis Med J 1991;90:170-171.

21. Yale SH, Limper AH. Pneumocystis carinii pneumonia in patients without acquired immunodeficiency syndrome: Associated illnesses and prior corticosteroid therapy. Mayo Clin Proc 1996;71:5-13.

22. Phair J, Munoz A, Detels $R$ et al. The risk of Pneumocystis carinii pneumonia among men infected with human immunodeficiency virus type 1 . N Engl J Med 1990;322:161-165.
23. Walzer PD, Perl DP, Krogstad DJ et al. Pneumocystis carinii pneumonia in the United States. Epidemiologic, diagnostic and clinical features. Ann Intern Med;1974;80:83-93.

24. Arend SM, Kroon FP, van't Wout JW. Pneumocystis carinii pneumonia in patients without AIDS, 1980 through 1993. Arch Intern Med 1995;155:2436-2441.

25. Sepkowitz KA, Brown AE, Telzak EE et al. Pneumocystis carinii pneumonia among patients without AIDS at a cancer hospital. JAMA 1992;267:832837.

26. Peters SG, Prakash UB. Pneumocystis carinii pneumonia. Review of 53 cases. Am J Med 1987;82:73-78.

27. Godeau B, Coutant-Perronne V, Le Thi Huong D et al. Pneumocystis carinii pneumonia in the course of connective tissue disease: Report of 34 cases. J Rheumatol 1994;21:246-251.

28. Chechani V, Bridges A. Pneumocystis carinii pneumonia in patients with connective tissue disease. Chest 1992;101:375-378.

29. Kane GC, Israel HL, Peters SP. Pneumocystis carinii pneumonia and methotrexate therapy. Chest 1993;103:1923.

30. Sepkowitz KA, Brown AE, Armstrong DA. Pneumocystis carinii pneumonia without acquired immunodeficiency syndrome. Arch Intern Med 1995; 155:1125-1128.

31. Pigrau C, Almirante B, Pahissa $A$ et al. Clinical presentation and outcome in cases of listeriosis. Clin Infect Dis 1993;17:143-144.

32. Kraus A, Cabral AR, Sifuentes-Osornio J, Alarcon-Segovia D. Listeriosis in patients with connective tissue diseases. J Rheumatol 1994;21:635-638.

33. Bula CJ, Bille J, Glauser MP. An epidemic of food-borne listeriosis in western Switzerland: Description of $\$ 7$ cases involving adults. Clin Infect Dis $1995 ; 20: 66-72$.

34. Ho JL, Shands $\mathrm{KN}$, Friedland $\mathrm{G}$ et al. An outbreak of type $4 \mathrm{~b}$ Listeria monocytogenes infection involving patients from eight Boston hospitals. Arch Intern Med 1986;146:520-524.

35. Champagne ET. Low gastric hydrochloric acid secretion and mineral bioavailability. Adv Exp Med Biol 1989;249:173-184.

36. Lewis JL, Rabinovich S. The wide spectrum of cryptococcal infections. Am J Med 1972;53:315-322.

37. Mcdonnell JM, Hutchins GM. Pulmonary cryptococcosis. Hum Pathol 1985;16:121-128.

38. Schimpff SC, Bennett JE. Abnormalities in cell-mediated immunity in patients with Cryptococcus neoformans infection. J Allergy Clin Immunol $1975 ; 55: 430-441$.

39. Steiner I, Polacheck I, Melamed E. Dementia and myoclonus in a case of cryptococcal encephalitis. Arch Neurol 1984;41:216-217.

40. Ludmerer KM, Kissane JM. Persistent fever and confusion in a healthy 70 year old man. Am J Med 1983;74:303-312.

41. Kass EH, Finland M. Corticosteroids and infections. Adv Intern Med 1958;9:45-80.

42. Dale DC, Petersdorf RG. Corticosteroids and infectious diseases. Med Clin North Am 1973;57:1277-1287.

43. Stuck AE, Minder CE, Frey FJ. Risk of infectious complications in patients taking glucocorticoids. Rev Infect Dis 1989;11:954-963.

44. Louria DB, Fallon N, Browne HG. The influence of cortisone on experimental fungus infections in mice. J Clin Invest 1960;39:1435-1449.

45. Schlech WF, Chase DP, Badley A. A model of food-borne Listeria monocytogenes infection in the Sprague-Dawley rat using gastric inoculation; development and effect of gastric acidity on infective dose. Int J Food Microbiol 1993;18:15-24.

46. Weksler ME. Senescence of the immune system. Med Clin North Am 1983;67:263-272.

47. Salzman RL, Peterson PK. Immunodeficiency of the elderly. Rev Infect Dis 1987;9:1127-1139.

48. Phair JP, Kauffman CA, Bjornson A et al. Host defenses in the aged: Evaluation of components of the inflammatory and immune responses. J Infect Dis 1978;138:67-73.

49. Davies PDO. Tuberculosis in the elderly. J Antimicrob Chemother 1994;34(A):93-100.

50. Kauffman CA. Fungal infections. Geriatr Clin North Am 1992;8:777-791.

51. Jacobs JL, Libby DM, Winters RA et al. A cluster of Pneumocystis carinii pneumonia in adults without predisposing illnesses. $\mathrm{N}$ Engl J Med 1991;324:246-250.

52. Weyand CM, Hicok KC, Hunder GG, Goronzy JJ. Tissue cytokine patterns in patients with polymyalgia rheumatica and giant cell arteritis. Ann Intern Med 1994;121:484-491. 